\title{
Observaciones sobre la relación entre economistas y políticos*
}

\author{
José R. SÁNCHEZ-FunG**
}

12 octubre, 2018

\begin{abstract}
Cómo citar: Sánchez-Fung, J. R. (2019). Observaciones sobre la relación entre economistas y políticos. Ciencia, Economía Y Negocios, 2 (2), 21-24. https://doi.org/10.22206/ceyn.2018. v2i2.pp21-24
\end{abstract}

Los economistas han logrado avances importantes desde que figuras como David Ricardo, Alfred Marshall, y A.C. Pigou aportaran ideas para el desarrollo de la economía como ciencia social; ver, por ejemplo, Blanchard (2000), Kumekawa (2017), y Galbraith (2017). En ese sentido, George Stigler (1965) comentó hace medio siglo: "Nuestra creciente producción de estudios teóricos y empíricos inevitablemente e irresistiblemente entrará en el ámbito de la política pública..." (p. 17). Stigler acertó, pero el entendimiento alcanzado por los economistas es difícil de comunicar y de convertir en planes concretos.

Por su parte, Rodrik (2015) presta especial atención a la posición de sectores de la sociedad en contra del libre comercio. El autor argumenta que la reacción es el resultado de implementar políticas de apertura comercial sin incorporar debidamente los potenciales beneficios y costos. El problema afecta marcadamente a los Estados Unidos, país con una gran cantidad de economistas profesionales al servicio del gobierno y del congreso, quienes además trabajan como asesores del sector privado. Rodrik especula que tanto los políticos como los economistas son responsables de esa situación.

La realidad es que conceptos teóricos como el dictador benevolente,

\footnotetext{
* Agradezco los comentarios de Harold Vázquez (editor de la revista) y Amelia U. Santos-Paulino. Los errores u omisiones son responsabilidad del autor.

** (a) Universidad de Nottingham, Ningbo, China. E-mail: JoseR.Sanchez-Fung@nottingham.edu.cn.
}

(b) Macroeconomic Policy and Development Advisory Group, 1200 Ginebra, Suiza. 
o el mundo ideal discutidos por Ronald Coase por ejemplo (2013), son difíciles de aplicar en la búsqueda del bien común (Buchanan, 1987; Tirole, 2017). En ese contexto, la gente espera que los economistas puedan (1) conciliar las sugerencias derivadas de modelos analíticos y hallazgos empíricos con (2) la posibilidad de diseñar políticas que necesitan aprobación en el congreso, y (3) una subsecuente implementación administrativa con (4) la finalidad de alcanzar un objetivo determinado. La dificultad de alcanzar el objetivo en cuestión, por ejemplo, una mejor distribución del ingreso, es evidente en la anécdota sobre el presidente que solicita un economista sin una mano para eliminar la disyuntiva causada cuando los economistas dan un consejo e inmediatamente ponderan otra posibilidad, por la expresión "en una mano tenemos que..., y en la otra..."

¿Qué podemos aprender de la experiencia reciente respecto a la relación entre economistas y políticos? Alan Blinder, profesor de economía en la Universidad de Princeton, escribe sobre su experiencia en los Estados Unidos. Blinder ocupó puestos importantes en el Consejo de Asesores Económicos del Presidente Clinton, y subsecuentemente en la Reserva Federal. Blinder señala elementos que complican la relación entre economistas y políticos: los diferentes horizontes temporales, la miopía notable (sesgo hacia resultados de corto plazo) de los políticos; la diferencia entre los incentivos, unos profesionales y otros marcados por objetivos electorales; y los fundamentos de las diferentes perspectivas analíticas que complican las discusiones sobre cuestiones 'positivas' y 'normativas'.

¿Qué sugiere Blinder para mejorar los resultados de la colaboración entre economistas y políticos? El principal consejo es delegar en tecnócratas el diseño y la ejecución de las políticas económicas. La forma en la cual opera la Reserva Federal ilustra la delegación de la política monetaria; otros bancos centrales, como el Banco (central) de Inglaterra y el Banco Central Europeo, también son dirigidos por tecnócratas, con prácticamente ninguna intervención por parte de los políticos ${ }^{1}$.

\footnotetext{
${ }^{1}$ Sánchez-Fung (2004) discute temas relacionados con especial referencia sobre el caso
} 
La delegación es importante pero también resulta imprescindible que los economistas sean capaces de exponer sus conocimientos a los políticos de modo accesible e inteligible. Y esto es difícil de lograr, particularmente en los países menos desarrollados. Sin embargo, las discusiones y sugerencias de Jean Tirole, ganador del Premio Nobel de Economía, y sus coautores (2017), reflejan la magnitud del reto para los economistas incluso en países avanzados como Francia.

Esa realidad nos lleva al caso de la República Dominicana. Indiscutiblemente, el país puede mejorar el proceso de diseño, aprobación, e implementación de las políticas económicas ${ }^{2}$. Por ejemplo, los cambios en la política fiscal son fuente de controversias en vista de la cantidad y la frecuencia de las reformas implementadas ${ }^{3}$. Las deficiencias en las reformas fiscales reflejan (1) las sugerencias de los economistas, (2) las decisiones de los políticos al momento de aprobar las reformas, o, una mezcla de (1) y (2). Esa situación de conflicto entre economistas y políticos y las deficiencias en las reformas fiscales que de dicha situación se derivan, aplica en el análisis de otros problemas de interés público, como la regulación de los servicios de salud y la política referente al comercio internacional.

La dinámica entre economistas y políticos es compleja en todas partes del mundo, incluyendo en la República Dominicana. Obviamente, la relación es imprescindible y debemos trabajar para mejorarla. No existe una fórmula única pero la literatura económica avanza ideas y estudia casos concretos que pueden servir de referencia.

\section{Referencias}

Andújar Scheker, Julio (2004) Economía política de las reformas: Un acercamiento teórico al caso dominicano. Ciencia y Sociedad, 29, 473-505.

\footnotetext{
de la política monetaria en la República Dominicana.

${ }^{2}$ Andújar Scheker (2004) estudia la economía política de las reformas usando como referencia el caso de la República Dominicana.

${ }^{3}$ Prazmowski (2017) discute las reformas fiscales en la República Dominicana desde la década de los 1960s
} 
Bénassy-Quéré, Agnès, Olivier J. Blanchard, y Jean Tirole (2017) What role for economists

in policy-making? Les notes du conseil d'analyse économique. French Council of Economic Analysis, no 42, Paris, Francia.

Blanchard, Olivier (2000) What do we know about macroeconomics that Fisher and Wicksell did not? Quarterly Journal of Economics, 115, 1375-1409.

Blinder, Alan S. (2018) Advise and Dissent: Why America suffers when economics and politics collide. New York, EEUU: Basic Books.

Buchanan, James M (1987) The constitution of economic policy. American Economic Review, 77, 243-250.

Coase, Ronald H. (2013) The problem of social cost. Journal of Law and Economics, 56, 837-877.

Galbraith, John Kenneth (2017) Economics in perspective. Princeton y Oxford, EEUU: Princeton University Press.

Kumekawa, Ian (2017) The first serious optimist: A.C. Pigou and the birth of welfare economics. Princeton y Oxford, EEUU: Princeton University Press.

Prazmowski, Peter A. (2017) The Laffer curve and tax distortions in the Dominican Republic. mimeo.

Rodrik, Dani (2015) Economics rules. New York y London: W.W. Norton \& Company.

Sánchez-Fung, José R. (2004) Reglas monetarias, metas de inflación y sus aplicaciones potenciales en la República Dominicana. Monetaria, 27, 291-323, julio/septiembre.

Stigler, George J. (1965) The economist and the state. American Economic Review, 60, 1-18.

Tirole, Jean (2017) Economics for the common good. Princeton y Oxford, EEUU: Princeton University Press. 